\title{
Out-of-hospital cardiac arrest: the importance of a registry
}

\author{
WY Wu *, FHKCEM, FHKAM (Emergency Medicine) \\ Hong Kong College of Emergency Medicine, Aberdeen, Hong Kong
}

*Corresponding author: wuwy@union.org

Hong Kong Med J 2019;25:176-7

https://doi.org/10.12809/hkmj197990

Out-of-hospital cardiac arrest (OHCA) is the most time-critical and challenging medical emergency. Patient survival depends on a "strong chain of survival" requiring the community, call centres, ambulances, and hospitals working together. Early cardiopulmonary resuscitation (CPR) and defibrillation are crucial for successful outcomes. Despite improvements in early intervention, improved surveillance, and increased public awareness in recent decades, the overall survival rate of OHCA remains low. According to the United States data in 2017, 10.4\% of OHCA patients survived to hospital discharge. ${ }^{1}$ In Europe, $10.3 \%$ of OHCA patients survived for at least 30 days or to hospital discharge. ${ }^{2}$ A study published in 2017 found that the figure for Hong Kong was even lower: only 2.3\% of OHCA patients survived for at least 30 days or to hospital discharge. ${ }^{3}$ Furthermore, knowledge of automatic external defibrillator use and first aid training among the general public in Hong Kong are also low. ${ }^{4}$

Researchers and medical practitioners have long searched for better interventions that may prevent cardiac arrest or reduce the number of deaths. Preventive measures such as screening for high-risk groups and using implantable cardioverterdefibrillators are effective in the prevention of cardiac arrest. However, these measures are costly and there are procedural and long-term risks, such as infection and device or lead malfunction, which limit their use and coverage. ${ }^{5}$ Therefore, OHCA remains a challenge and initiatives aimed at optimising the quality and outcome of resuscitation are important. The Resuscitation Academy of the United States ${ }^{6}$ has published numerous initiatives to improve OHCA survival, among which setting up a Cardiac Arrest Registry was considered as the first step for continuous quality improvement.

In 2015, the Institute of Medicine published a report titled Strategies to Improve Cardiac Arrest Survival: A Time to $A c t^{7}$ that emphasised the significance of establishing a National Cardiac Arrest Registry as the first recommendation out of eight. In this issue of the Hong Kong Medical Journal, Lui et $\mathrm{al}^{8}$ review OHCA registries worldwide and discuss the urgent need for a territory-wide registry for OHCA. They argue that setting up such a registry is a critical step to improve the outcomes of OHCA in
Hong Kong as it enables data-driven assessment of the process and outcomes of OHCA management. Through ongoing and systematic collection of highquality data, improvement efforts can be tracked, benchmarked, and refined..$^{9}$ Data collected through an OHCA registry could enable high-quality research to identify areas for improvement that would strengthen the chain of survival. ${ }^{10,11}$ However, effective implementation can be challenging. The government plays a crucial role in assembling resources, infrastructure, and personnel that will be required to successfully establish, implement and sustain an OHCA registry. It may be practical to set up a government-led committee to govern and manage the registry. Emergency medical services personnel and healthcare workers would be ideally placed to oversee the overall operation of the registry and ensure consistent data contributions.

Data collected through an OHCA registry can be used for analysis and for planning improvements. In addition, these data can reveal controversial aspects of cardiac arrest. Also in this issue of the Hong Kong Medical Journal, So et $\mathrm{al}^{12}$ discuss the difficulties of making a declaration of medical futility and a decision on termination of resuscitation (TOR). The decision of TOR is difficult to make but it can help reduce futile medical care of OHCA patients. ${ }^{13}$

Despite researchers working hard to refine the guidelines for TOR best practice, the discussion over when to stop resuscitation remains controversial. Clinical judgement will always be critical in deciding TOR timing; however, surveillance data from an OHCA registry can provide more objective figures for medical researchers to analyse and establish better guidelines for TOR. It is extremely important that TOR guidelines are regularly updated with the latest surveillance data analysis and advances in medical technology.

An OHCA registry is a fundamental source of data for cardiac arrest and a cornerstone for understanding the current OHCA burden as well as for designing effective improvement plans. Potential roles for an OHCA registry extend far beyond epidemiological research, from deployment of resources to health economics, from the evaluation of bystander CPR to monitoring the OHCA outcomes, and from outcome improvement to the development of guidelines. Despite efforts 
by researchers and medical professionals to uphold the current standards, the survival rate of OHCA in Hong Kong remains very low. Hong Kong has already implemented successful policies on protection of rescuers and public access to defibrillators. ${ }^{14,15}$ Given the successful experiences from nearby countries such as Japan and Singapore that have introduced OHCA registries, ${ }^{16-18}$ it is of pressing need to establish such a territory-wide OHCA registry in Hong Kong.

\section{Author contributions}

The author contributed to the study, approved the final version for publication, and takes responsibility for its accuracy and integrity.

\section{Conflicts of interest}

The author has disclosed no conflicts of interest.

\section{Funding/support}

This editorial received no specific grant from any funding agency in the public, commercial, or not-for-profit sectors.

\section{References}

1. Cardiac Arrest Registry to Enhance Survival, United States. CARES Annual Report 2017. Available from: https:// mycares.net/sitepages/uploads/2018/2017flipbook/index. html?page=26. Accessed 1 Apr 2019.

2. Gräsner JT, Lefering R, Koster RW, et al. EuReCa ONE-27 Nations, ONE Europe, ONE Registry: A prospective one month analysis of out-of-hospital cardiac arrest outcomes in 27 countries in Europe. Resuscitation 2016;105:18895.

3. Fan KL, Leung LP, Siu YC. Out-of-hospital cardiac arrest in Hong Kong: a territory-wide study. Hong Kong Med J 2017;23:48-53.

4. Fan KL, Leung LP, Poon HT, Chiu HY, Liu HL, Tang WY. Public knowledge of how to use an automatic external defibrillator in out-of-hospital cardiac arrest in Hong Kong. Hong Kong Med J 2016;22:582-8.

5. Marine JE, Russo AM. Primary prevention of sudden cardiac death in heart failure and cardiomyopathy. Available from: https://www.uptodate.com/contents/primary-prevention-ofsudden-cardiac-death-in-heart-failure-and-cardiomyopathy. Accessed 15 May 2019.

6. Resuscitation Academy, United States. 10 Steps for improving survival from cardiac arrest. 2010. Available from: http://www. resuscitationacademy.org/downloads/ebook/10_steps_2018. pdf. Accessed 1 Apr 2019.

7. Robert G, Margaret AM, Andrea MS. Strategies to Improve Cardiac Arrest Survival: A Time to Act. Board on Health Sciences Policy; Institute of Medicine, Washington (DC): National Academies Press (US); 2015.

8. Lui CT, Lau CL, Siu AY, Fan KL, Leung LP. Hong Kong needs a territory-wide registry for out-of-hospital cardiac arrest. Hong Kong Med J 2019;25:222-7.

9. Rajagopal S, Booth SJ, Brown TP, et al. Data quality and 30-day survival for out-of-hospital cardiac arrest in the UK out-of-hospital cardiac arrest registry: a data linkage study. BMJ Open 2017;7:e017784.

10. Van Diepen S, Jollis J, Granger C. Use of the national CARES Registry to guide quality improvement efforts to improve survival from out of hospital cardiac arrest in North Carolina. J Am Coll Cardiol 2012;59:E734.

11. Nehme Z, Bernard S, Cameron P, et al. Using a cardiac arrest registry to measure the quality of emergency medical service care: decade of findings from the Victorian Ambulance Cardiac Arrest Registry. Circ Cardiovas Qual Outcomes 2015;8:56-66.

12. So CW, Lui CT, Tsui KL, et al. Questionnaire survey on medical futility and termination of resuscitation in cardiac arrest patients among emergency physicians in Hong Kong. Hong Kong Med J 2019;25:183-91.

13. Podrid PJ. Prognosis and outcomes following sudden cardiac arrest in adults. Available from: https://www.uptodate. $\mathrm{com} /$ contents/prognosis-and-outcomes-following-suddencardiac-arrest-in-adults?search $=$ termination $\% 20$ of $\% 20$ resuscitation\&source $=$ search_result\&selectedTitle $=1 \sim 150 \&$ usage_type=default\&display_rank=1. Accessed 15 May 2019.

14. Wai AK. Protection of rescuers in emergency care: where does Hong Kong stand? Hong Kong Med J 2017;23:656-7.

15. Siu AY. Public access defibrillation: the road ahead. Hong Kong Med J 2017;23:554-5.

16. American Heart Association:Out-of-hospital chain of survival. 2018. Available from: https://cpr.heart.org/AHAECC/ CPRAndECC/AboutCPRFirstAid/ CPRFactsAndStats/UCM_ 475731_CPR-Chain-of-Survival.jsp. Accessed 1 Apr 2019.

17. McNally B. The importance of cardiac arrest registries. Scand J Trauma Resusc Emerg Med 2014; 22(Suppl 1):A3.

18. Doctor NE, Ahmad NS, Pek PP, Yap S, Ong ME. The PanAsian Resuscitation Outcomes Study (PAROS) clinical research network: what, where, why and how. Singapore Med J 2017;58:456-8. 